\title{
Stock Price Reactions to ESG News: The Role of ESG Ratings and Disagreement
}

\author{
George Serafeim and Aaron Yoon*
}

\begin{abstract}
We investigate whether ESG ratings predict future ESG news and the associated market reactions. We find that the consensus rating predicts future news, but its predictive ability diminishes for firms with large disagreement between raters. Relation between news and market reaction is moderated by the consensus rating. In the presence of high disagreement between raters, the relation between news and market reactions weakens while the rating with most predictive power predicts future stock returns. Overall, while rating disagreement hinders the incorporation of value relevant ESG news into prices, ratings predict future news and proxy for market expectations of future news.
\end{abstract}

\footnotetext{
* We thank Caroline Flammer, Soohun Kim, Zengquan Li, and seminar participants at KAIST, Korea Securities Association, and TruValue Labs ESG Conference for helpful comments. George Serafeim is the Charles M. Williams Professor of Business Administration at Harvard Business School. Aaron Yoon is an Assistant Professor at Kellogg School of Management at Northwestern University. Serafeim is grateful for financial support from the Division of Faculty Research and Development at Harvard Business School. We are grateful to TruValue Labs and Sustainalytics for providing access to their ESG data. All errors are our sole responsibility. Corresponding author: Aaron Yoon. 2211 Campus Drive, \#4421. Evanston IL 60201. Tel: +1-847-491-2662. Fax: +1-847-467-1202. Email: aaron.yoon@kellogg.northwestern.edu.
} 


\section{INTRODUCTION}

Proper allocation of resources in an economy requires institutions that provide information intermediation (Healy and Palepu 2001). As a result, a large amount of resources is spent in producing performance evaluations, such as sell-side analyst forecasts, recommendation ratings and credit ratings. A central feature is an eventual realization that disciplines those evaluations, such as future stock returns in the case of investment recommendations (Barber, Lehavy, McNichols, and Trueman 2001; Clement and Tse 2003; Gleason and Lee 2003), realized earnings in the case of analyst forecasts (Mikhail, Walther, and Willis 1999; Bradshaw, Drake, Myers, and Myers 2012; Hong and Kubik 2003), and default on debt in the case of credit ratings (Becker and Milbourn 2011).

In this paper, we focus on a relatively newer set of performance evaluations: environmental, social and governance (ESG) ratings. These ratings now are sourced by investment managers with trillions of dollars in assets under management influencing portfolio construction and trading (Amel-Zadeh and Serafeim 2018). However, due to their multidimensionality and the difficulty in clearly observing the outcomes associated with ESG performance, it is much less clear how one can or should judge their quality. As a result, an emerging stream of literature has focused on the fact that different raters give the same company very different ratings (Berg, Koelbel and Rigobon 2019; Christensen, Serafeim and Sikochi 2019) raising questions about their usefulness (Chatterji, Durand, Levine, and Touboul 2016).

Against this backdrop, we focus on three key questions. First, do ESG ratings predict future ESG news and how rater disagreement affects this predictive ability? Using data from the three large ESG rating providers (i.e., MSCI, Sustainalytics and Thomson Reuters), we test the usefulness of ESG ratings by examining whether the latest outstanding consensus (i.e. average 
across the three) ESG rating predict future ESG news. We source a dataset on ESG news from TruValue Labs, which is a data provider that analyzes big data using natural language processing and sentiment analysis to classify the news as positive or negative. ${ }^{1}$ The dataset provides daily firm-specific measures of positive or negative news for ESG topics, such as employee well-being, product safety, energy management, and business ethics.

Ex ante, the relation between ESG ratings and news is not clear. For example, as SEC Chairman Jay Clayton recently pointed out, ESG ratings may be noisy and would lead to imprecise investment analysis especially when considered in aggregate. ${ }^{2}$ On the other hand, ESG ratings may predict future ESG news if they somewhat accurately capture a firm's activities and strategies to limit negative ESG events (i.e. workplace accidents, product safety related recalls, corruption allegations, environmental pollution) and promote positive ESG events (i.e. recognition as a great workplace, launch of environmental solutions products, meeting safety milestones) . In our first empirical analysis, we find a strong positive predictive relation between ESG ratings and news. But we also document that the predictive value of the consensus ESG rating is much weaker in the presence of significant disagreement, consistent with disagreement impairing the predictive value of the consensus rating.

The second question relates to how consensus rating and disagreement affect stock reactions around the ESG news. We measure stock reactions as the industry-adjusted stock returns on the three-day window between one day before and after the news. Our expectation is that, if ESG news are value relevant, the stock price reaction will be positive (negative) for positive

\footnotetext{
${ }^{1}$ The data from TruValue Labs track ESG-related information every day across thousands of companies and classify news to positive or negative. This dataset includes information from a wide variety of sources-including reports by analysts, media, advocacy groups, and government regulators - and emphasizes that the measures focus on vetted, reputable, and credible sources that are likely to generate new information and insights for investors.

${ }^{2}$ Financial Times. May 28, 2020. SEC chair warns of risks tied to ESG ratings.
} 
(negative) ESG news. In addition, we expect that the market reaction spread between positive and negative news would be considerably smaller for firms with high ESG ratings. This is because for firms where investors expect positive news, there would be little stock price reaction as the prices already incorporate the positive news. However, we expect that negative news will generate reactions that are similar across the sample of firms with low or high consensus ratings, consistent with negative news having information content even when market participants assess a firm as a poor ESG performer.

We find a positive market reaction to positive ESG news and negative reaction to negative news. In addition, the reaction to positive news is associated with 75 basis points higher stock returns than negative news in firms with low average ESG Score. However, for firms with high consensus ESG ratings, we find that the return spread between positive and negative news is only 34 basis points. This suggests that market reaction to positive news is smaller for firms with high ESG rating because much of the positive news is already reflected in stock prices.

Given that past literature highlights that not all ESG issues are financially material for companies in a given industry (Khan, Serafeim and Yoon 2016; Grewal, Hauptmann, and Serafeim 2020), we separate our sample to news that are likely to be financially material or not for a given industry. We find that the stock reaction results are generally much larger in the financially material sample. ${ }^{3}$ For example, the stock reaction spread between positive and negative news increases to $2.81 \%$ for firms with low consensus rating but the spread is 79 basis points for firms with high consensus rating. We also predict and find that for firms with low disagreement, where ratings are more likely to create stronger expectations about future news, the results are further

\footnotetext{
${ }^{3}$ We separate the sample using materiality classifications from the Sustainability Accounting Standards Board (SASB), the classification also used by TruValue Labs.
} 
magnified. The stock reaction spread between positive and negative news increases to $3.70 \%$ for firms with low consensus rating and 73 basis points for firms with high consensus rating.

In the presence of high disagreement, we find a lack of significant market reactions to news and that the consensus rating does not moderate the relation between news and market reactions. To understand whether disagreement might obscure the incorporation of ratings that contain information about future news in prices, our third analysis is on the predictive power of ratings on future stock returns. First, we document which ratings have forecasting power over future news in the presence of rating disagreement. Given this relationship, we then examine whether the most predictive rating can be used to predict future stock returns for a sample of companies with high disagreement. Specifically, we buy the firms with the most predictive rating above the average of the two other ratings and sell the firms with the most predictive rating below the average of the other two. The long (short) portfolio is expected to have more positive (negative) ESG news in the future. We find that the long/short portfolio yields an equal-weighted (value-weighted) annualized alpha of $4.27 \%(4.00 \%)$, suggesting that the discrepancy between the raters acts as an impediment to timely incorporation of the most accurate rating with respect to news into prices.

Our paper contributes to several streams of literature. First, we contribute to the literature that examines the properties of ESG ratings. For example, Chatterji et al. (2016) document lack of agreement across social ratings from six well established raters, Berg et al. (2019) find that the source of divergence in ESG ratings is from scope and measurement, and Christensen et al. (2019) finds that greater ESG disclosure exacerbates disagreement across ESG ratings. We add to this stream of literature by providing evidence that ESG ratings can be useful in predicting future news and we are the first to examine this forecasting ability of ESG ratings with respect to news. We 
also find that in the presence of significant disagreement that usefulness declines, but investors can take advantage of this feature to enhance portfolio decisions.

Moreover, our results suggest that ratings also affect market reactions to ESG news. Thereby, we provide evidence on how ESG ratings create investor expectations about future news and that disagreement is associated with lack of stock price reactions. These latter findings contribute to a literature that examines market reactions to ESG news (Flammer 2013; Dimson, Karakas, and Li 2015; Krüger 2015; Capelle-Blancard and Petit 2019; Grewal, Riedl and Serafeim 2019; Naughton, Wang, and Yeung 2019). Despite significant research efforts have been devoted to analyzing a firm's ESG activities, the literature has not yet examined how investors react to ESG news after accounting for the existing expectations about a firm's ESG activities.

In addition, our paper is related to the literature that examines why investors might react to ESG news. One explanation is that investors react because of nonpecuniary reasons (Jones, Jones, and Little 2000; Wether and Chandler 2005; Baker, Bergstresser, Serafeim, and Wurgler 2018). Under this explanation, ESG information is value irrelevant and therefore financially immaterial. In such a case, we expect the reaction to be significant for any ESG issue regardless of its financial materiality, which is contrary to what we find. A different stream of literature argues that ESG news convey value-relevant information about a firm's future growth, risk, and competitive positioning (Khan et al. 2016; Grewal et al. 2019). We add to this stream of literature by showing that the market reaction is driven mostly by news that are classified as financially material. Overall, our results are supportive of the view that investors differentiate in their reactions based on whether the news is likely to affect a company's fundamentals, and therefore their reactions are motivated by a financial rather than a nonpecuniary motive. 
The remainder of the paper is organized as follows. The next section provides the motivation, literature review and our hypotheses. Section 3 presents a description of the data and sample. Section 4 presents the research design and results. Section 5 concludes.

\section{MOTIVATION, LITERATURE REVIEW AND HYPOTHESES DEVELOPMENT}

\section{Ratings and News}

Environmental, social, and governance (ESG) issues in business has been a fast-growing phenomenon and much attention has been paid by companies in recent years. For example, there were fewer than 20 publicly listed companies that issued reports that included ESG data in the early 1990s. By 2014, this number had increased to nearly 6,000 (Serafeim 2014). This growing salience of ESG is not unique just to companies but also prevalent in the asset management industry. For example, UN PRI signatories only had a few hundred billion dollars in AUM in the first few years starting in 2006 , but the AUM reached $\$ 80$ trillion by 2019 . Forbes pointed out such massive inflow of capital into ESG as "remarkable" and the Wall Street Journal pointed out that more companies are investing resources in better communicating their ESG efforts and regulators are placing an increasing emphasis on understanding how ESG information flows to the market, seeking to learn how capital-market participants react to this information. ${ }^{4,5}$

A central piece of the ESG information environment is the concept of ESG ratings that is produced by various raters. These ratings seek to inform decision makers how well a firm is managing its ESG risks and opportunities and are utilized by many investors. Raters use proprietary methodologies, including hundreds of metrics and then weighing those metrics to produce an aggregate rating. Recent evidence suggest that those ratings diverge significantly, as a

\footnotetext{
${ }^{4}$ Forbes. The Remarkable Rise of ESG. Jul 11, 2018.

${ }^{5}$ WSJ. ESG Funds Draw SEC Scrutiny. Dec 16, 2019.
} 
result leading to severe criticism about their usefulness (Chatterji et al. 2016; Berg et al. 2019). Moreover, because it is not clear how one could ex-post assess their validity, this has likely led to persistence in rater disagreement over time and in fact recent evidence suggest that this disagreement has been increasing over time (Christensen et al. 2019). Against this backdrop, there has been significant interest in understanding the properties of ESG ratings.

Ex ante, the relation between ESG ratings and news is not clear. If ESG ratings appropriately reflect the efforts that a management makes to limit negative ESG events and to promote positive ESG events, then there should be a positive and significant relation between ESG ratings and more positive news. But if these ratings are plagued with noise and they do not accurately reflect management efforts, they will bear no relationship with how positive vs negative news will be (Chatterji et al. 2016). Our first hypothesis then is:

$H_{1}$ : There is a positive relationship between ESG ratings and more positive future ESG news.

Our second hypothesis suggests the relationship between ESG ratings and news will be moderated by rater disagreement. We expect that in the presence of disagreement, ratings will be less likely to accurately predict future news as the disagreement in ratings reflects different evaluators reaching a different conclusion about the extent to which management efforts are adequate or not. Our second hypothesis is:

$\mathrm{H}_{2}$ : The relationship between ESG ratings and more positive future ESG news will be negatively moderated by the level of rater disagreement.

\section{Ratings, News and Stock Reactions}

Numerous papers have examined how the market reacts to ESG related events. For example, Grewal et al. (2019) examined market reactions around the announcement of the ESG 
disclosure mandate in the European Union and documented less negative market reaction for firms that have high ESG disclosure. Naughton et al. (2019) found that announcements of ESG activities generate positive abnormal returns during periods when investors place a valuation premium on ESG performance, Flammer (2013) found that the market reacts positively to the announcement of eco-friendly initiatives, and Dimson et al.(2015) found positive abnormal returns to successful ESG engagements by investors. Capelle-Blancard and Petit (2019) found negative market reaction to negative ESG news.

This stream of literature suggests that ESG information may be related to shareholder value. The argument is that better ESG performance could translate into value because of operating efficiencies, stronger brand and customer loyalty, and employee engagement (Fombrun and Shanley 1990; Turban and Greening 1997; Freeman, Harrison, and Wicks 2007; Edmans 2011; Eccles, Ioannou, and Serafeim 2014; Lins, Servaes and Tamayo 2017). However, we note that another stream of literature suggests that a firm's ESG efforts are associated with agency costs. In such a case, ESG would mainly enhance managers' reputation at the expense of shareholders (Cheng, Hong, and Shue 2013). This would lead to a rise in a firm's costs which would also be a disadvantage in a competitive market (Friedman 1970; Jensen 2002) and lead to negative market reactions to positive ESG news (Krüger 2015). Under this scenario, $\mathrm{H}_{3}$ below will be rejected: H3: More positive ESG news will be associated with more positive stock price reactions to the news.

We expect that the relationship between news and stock price reactions will be moderated by the consensus ESG rating. We know from prior literature that examined financial analyst forecast and bond ratings that forecasts shape market expectations but also that some changes in forecast would be already anticipated and priced in by the market (Fried and Givoly 1982; Goh 
and Ederington 1993). Similarly, our hypothesis is that ESG ratings might shape market expectations about future ESG news and thereby have an effect on the associated market reactions. Specifically, we expect that firms with low consensus ESG ratings would react more strongly to positive news rather than the firms with high ESG ratings.

As for negative news, our prediction has a nuanced difference vis-à-vis that on the market reaction to positive news (Pinello 2008). Specifically, we predict that negative news would likely generate negative market reaction regardless of how firm ESG efforts are rated. This is because negative news would likely generate public controversies and scrutiny from the media that serves a watchdog for negative news (Miller 2006; Lee, Hutton, and Shu 2015). These arguments would lead to our fourth hypothesis:

$H_{4}$ : For positive ESG news, the relationship between ESG news and stock price reactions will be negatively moderated by ESG ratings.

Next, we make predictions on the role of rater disagreement. We expect that in the presence of high rater disagreement the relationship between ratings and news will be weaker as investors might be confused in interpreting the news. In addition, rater disagreement will likely mitigate the moderating role of ESG ratings in the presence of disagreement as the consensus ESG rating is less likely to be a meaningful measure of investor expectations. Our fifth hypothesis is as follows: $H_{5}:$ The positive relationship between ESG news and stock price reactions and the moderating role of ESG ratings will be weaker in the presence of rater disagreement.

We note that we expect these relations to be stronger for ESG issues that are likely to be financially material for companies in each industry. Recent literature has shown that only a small subset of ESG issues in each industry are associated with future stock returns and accounting performance (Khan et al. 2016) or that disclosure around those ESG issues is related to more firm- 
specific information in stock prices (Grewal et al. 2020). Therefore, we document all these relations also separately for a sample that relates to likely financially material ESG news, as identified by the Sustainability Accounting Standards Board (SASB).

\section{DATA AND SAMPLE}

\section{ESG News Data}

We use TruValue Labs data that tracks ESG-related information every day across thousands of companies and classify that news as positive or negative. TruValue Labs sources news from outside the organization including a wide variety of sources such as analyst reports, various media, advocacy groups, and government regulators. TruValue Labs emphasizes that its measures focus on vetted, reputable, and credible sources that are likely to generate new information and therefore insights for investors. To increase transparency and validate the data, the TruValue Labs platform allows a user to track the original source of the articles and events that inform the sentiment analysis for each specific issue. The platform aggregates unstructured data from over 100,000 sources into a continuous stream of ESG data for monitored companies.

Every day, TruValue Labs uses machine learning to find ESG-relevant articles for each company and classify the news not only to positive versus negative in a binary way, but also degrees of positivity or negativity and whether the news is financially material to the company or not using the SASB classification. Their proprietary system uses natural language processing (NLP) to interpret semantic content and generate analytics scoring data points on performance and also inform the data users how many news articles that their score is based on. ${ }^{6}$ For example, Ingersoll Land had positive sentiment following news on the firm's investments to improve waste

\footnotetext{
${ }^{6}$ Our sample uses ESG News score that have at least five articles, because the algorithm used in TruValue Labs' sentiment analysis requires at least a few articles to be accurate.
} 
and hazardous-materials management, materials sourcing, and product safety. In contrast, Facebook had negative sentiment following news on the firm's data-privacy issues, concerns about regulatory pressure, and user rights.

In addition, their process would assign a more negative score to a catastrophic oil spill affecting several workers and communities and a less negative score to a workplace incident that leads to a minor injury for one worker. TruValue Labs assigns such scores in a consistent manner based on the semantic content across data points, so that if there is hypothetically an identical event such as the catastrophic oil spill and an identical discussion of the event in a textual document, the sentiment-based score for such an event would be the same.

TruValue Labs data uses a scale of 0 (most negative) to 100 (most positive). An ESG News Score of 50 represents a neutral impact. Scores above 50 indicate positive sentiment, and scores below 50 reflect negative sentiment.

\section{ESG Ratings Data}

Our first source of ESG Ratings data is from MSCI ESG Ratings, which is considered the largest ESG data vendor by the investment community (Christensen et al. 2019). MSCI ESG Ratings rating ranges from 0 (most negative) to 10 (most positive). The second and third ratings are from Sustainalytics and Thomson Reuters Asset 4. These ratings range from 0 (most negative) to 100 (most positive). We multiply MSCI's ratings by 10 to make them comparable to the two other sources. With the three ESG Ratings data that are all now out of 100, we define Average ESG Rating as the average of the most recent ESG Rating from MSCI, Sustainalytics, and Thomson Reuters and disagreement is defined as the standard deviation of these ESG Ratings, following Christensen, Serafeim and Sikochi (2019). As we describe later, we also replicate our 
analysis after we normalize each ESG score to all exhibit same average and standard deviation. All results remain similar, independent if we use the raw or normalized scores.

\section{Other Data}

We use Compustat and CRSP to construct the return related and firm level variables. Industry Adjusted Return $-1,+1$ is the industry (six-digit GICS) adjusted return during the three days around the news. $\log ($ Market Cap) is the log of beginning-of-day market capitalization for a firm on the day the news article is published. MTB is beginning-of-day market value over book value of equity. ROE is defined as net income over average shareholder equity. Leverage is longterm debt plus current debt over the average of total assets of the current and previous year. Capex/PPE is capital expenditure divided by property plant and equipment. SG\&A/Sales is selling, general, and administrative expense over sales. Adv Exp/Sales is advertising expense over sales. $\mathrm{R} \& \mathrm{D} /$ Sales is $\mathrm{R} \& \mathrm{D}$ expense over sales. We obtain the five risk factors used in Fama and French (2016) from Kenneth French's website.

\section{Sample}

Table 1 presents the frequency table. Panel A presents the table by year. There are 1227 observations in $2011,1,869$ observations in $2011,1,845$ observations in 2012, 2,030 observations in $2013,3,069$ observations in $2014,5,799$ observations in $2015,5,468$ observations in $2016,6,516$ observations in 2017, and 3,758 observations in 2018. We note that 2018 has 3,758 , because we obtained TruValue Labs' news data until June 2018. Panel B presents the table by GICS sector. There are 1,498 observations in the Energy sector, 1,505 observations in the Materials sector, 2,644 observations in the Industrials sector, 5,632 observations in the Consumer Discretionary sector, 
4,078 observations in the Consumer Staples sector, 3,601 observations in the Health Care sector, 1,729 observations in the Financials sector, 6,253 observations in the Information Technology sector, 3,319 observations in the Communication Services sector, 1,504 observations in the Utilities sector, and 91 observations in the Real Estate sector.

Table 2 presents the descriptive statistics. Panel A shows the summary statistics. Our total sample includes 31,854 unique firm-day observations with ESG news between January 2010 and June 2018. Industry Adjusted Return $-1,+1$ has mean and median of 0.00 . ESG News which ranges from 0 (most negative) to 100 (most positive) has a mean and median of 56.26 and 56.53 suggesting that news is tilted slightly towards the positive side. The average MSCI, Sustainalytics, and Thomson Reuters ESG Ratings are 48.47, 62.22, and 70.70, respectively. Average ESG Rating has a mean of 58.76 and Disagreement has a mean of 10.28. As for other firm level characteristics, an average firm has a $\log ($ Market Cap) of 17.90, MTB of 4.89, ROE of 0.20, Leverage of 0.27, Capex/PPE of 0.12, SG\&A /Sales of 0.22, Adv Exp/Sales of 0.02, and R\&D/Sales of 0.06.

Panel B presents the correlation table. The correlation between ESG News and MSCI ESG Rating, Sustainalytics Rating, Thomson Reuters Rating, Average ESG Rating are 0.30, 0.25, 0.06, and 0.25 , respectively, suggesting that ESG News is positively correlated to ESG Ratings from MSCI and Sustainalytics. The correlation between MSCI ESG Rating and Sustainalytics ESG Rating is 0.47 and that between MSCI ESG Rating and Thomson ESG Rating is 0.30. This is consistent with the literature (e.g., Berg et al. 2019) that points out that ESG Ratings are not highly correlated amongst each other. The correlation between $\log$ (Market Cap) and Average ESG Rating, and Disagreement are 0.42 and 0.29 , suggesting that larger firms have higher average ESG performance ratings from raters but also are subject to more disagreement between the raters. 


\section{RESEARCH DESIGN AND RESULTS}

\section{Prediction of News Based on Consensus ESG Rating}

We first test whether ESG ratings predict future ESG news and how rater disagreement affects their predictive ability. To do so, we examine whether the latest outstanding consensus ESG rating is associated with future ESG news. Specifically, we use the following empirical specification:

$$
\begin{aligned}
& \text { ESG News }_{i, t}=\beta_{0}+\beta_{1} \text { Average ESG Rating }_{i, t-1}+\text { Control Variables }+ \text { Date FE }+ \\
& \text { Industry } F E+\varepsilon_{i, t} \text { (1a) } \\
& \text { ESG News }_{i, t}=\beta_{0}+\beta_{1} \text { Average ESG Rating }_{i, t-1}+\beta_{2} \text { Disagreement }_{i, t-1}+ \\
& \beta_{3} \text { Average ESG Rating }_{i, t-1} * \text { Disagreement }_{i, t-1}+\text { Control Variables }_{+} \text {Date FE }+ \\
& \text { Industry } F E+\varepsilon_{i, t}(1 b)
\end{aligned}
$$

where ESG News is the ESG news score from TruValue Labs. Average ESG Rating is average of the most recent ESG ratings from MSCI, Sustainalytics, and Thomson. Disagreement is the standard deviation of these ESG ratings.

Control variables include the following variables. Log(Market Cap) is the log of beginningof-day market capitalization for a firm on the day the news article is published. MTB is beginningof-day market value over book value of equity. ROE is defined as net income over average shareholder equity. Leverage is long-term debt plus current debt over the average of total assets of the current and previous year. Capex/PPE is capital expenditure divided by property plant and equipment. SG\&A/Sales is selling, general, and administrative expense over sales. Adv Exp/Sales is advertising expense over sales. $R \& D / S a l e s$ is $R \& D$ expense over sales. We also control for date and industry fixed effects. Standard errors are robust to heteroscedasticity and double clustered at the firm and date level.

We present the results in Table 3. Column 1 presents the result from equation 1a using All News in TruValue Labs as the ESG News. The coefficient estimate on Average ESG Rating $\mathrm{t}_{-1}$ is 
0.2784 (t-stats: 7.446). As predicted by H1, this suggests that ESG ratings predict ESG news. We separate Average ESG Rating into quintiles and deciles to provide additional evidence on the monotonicity of the relation (Appendix Table 2). Quintile 2 indicates the firms with Average ESG Ratings in the $2^{\text {nd }}$ lowest quintile and Quintile 5 indicates the firms with Average ESG Ratings in the highest quintile during the year. Decile 2 indicates the firms with Average ESG Ratings in the $2^{\text {nd }}$ lowest decile and Decile 10 indicates firms with Average ESG Ratings in the highest decile during the year. In both specifications, firms with the lowest average ESG rating serve as the benchmark. We observe a monotonic increase in the positivity of the news across the portfolio of firms.

Column 2 presents the result from equation $1 \mathrm{~b}$ using All News in TruValue Labs as the ESG News but also present evidence on the moderating effect of disagreement in ratings. The coefficient estimates on Average ESG Rating $\mathrm{t}_{-1}$, Disagreement, and Average ESG Rating ${ }_{\mathrm{t}-1}$ * Disagreement are 0.3975 (t-stats: 7.293$), 0.6080$ (t-stats: 2.248), and -0.0127 (t-stats: -2.881). As in column 1, ESG Rating predicts ESG News. However, as predicted in $\mathrm{H} 2$, this relationship is negatively moderated by the disagreement between raters. In sum, while the latest ESG rating predicts ESG news, the predictive value of the consensus ESG rating is much weaker in the presence of significant disagreement.

In columns 3 and 4, we present results using a subsample of observations that relate to News on ESG issues that are likely to be financially material. We separately report results using that subsample given that they are likely to be more economically significant events. Column 3 presents the result from equation 1a. The coefficient estimate on Average ESG Rating $\mathrm{t}_{-1}$ is 0.2458 (t-stats: 5.186). In column 4, we present the results from equation $1 \mathrm{~b}$ and the coefficient estimates on Average ESG Rating $\mathrm{t}_{\mathrm{t}-1}$, Disagreement, and Average ESG Rating $\mathrm{t}_{\mathrm{t}-1}$ * Disagreement are 0.4132 
(t-stats: 6.237), 0.8904 (t-stats: 2.882), and -0.0167 (t-stats: -3.341). As in columns 1 and 2, we also find that ESG Rating predicts ESG News and that disagreement moderates this relationship.

For robustness, we replicate the results presented in Table 3 using normalized ESG ratings (i.e., calculating Average ESG Rating t-1 $_{1}$ and Disagreement by normalizing ESG ratings from MSCI, Sustainalytics, and Thomson). We present this evidence in Appendix Table 1 and omit detailed discussion as the inferences are essentially identical. We also examine whether ESG Ratings predict News on ESG issues that are likely to be financial immaterial. We find that ESG Rating predicts Immaterial ESG News, but the moderating effect of Disagreement is significantly weaker than Table 3 where we used All ESG News and Material ESG News as dependent variables. We present this evidence in Appendix Table 3 Panel A.

\section{Market Reaction to ESG News Conditional on the Average ESG Rating}

In this section, we examine the market reaction to ESG news and the role of consensus ESG rating and disagreement in mediating this relationship. Table 4 first presents the univariate analysis examining market reaction to ESG news. We use Industry Adjusted Return $-1,+1$ as the outcome variable. Panel A presents the results using All News from TruValue Labs. Consistent with the prediction in $\mathrm{H} 3$, we find that positive (negative) ESG news is associated with positive (negative) stock price reaction. We separate the sample into those with high and Average ESG Rating and examine their market reaction to positive or negative news.

In the univariate analyses, the results show that the average industry adjusted return for the group of firms with high Average ESG Rating is $0.0738 \%$ for positive news, and that for the group of firms with low Average ESG Rating is $0.4159 \%$. As for negative news, the average industry adjusted return for group of firms with high average ESG Rating is $-0.1890 \%$, and that for the group of firms with low Average ESG Rating is $-0.2184 \%$. Our findings suggest that when 
investors expect positive news, there is little stock price reaction as the prices already incorporate this positive news. However, for negative news, reactions are similar across the sample of firms with low or high consensus ESG ratings.

In Panel B, we consider news that are material and examine the role of consensus ESG rating in moderating the relationship between market reaction and news. As for positive news, the average industry adjusted return for the group of firms with high Average ESG Rating is $0.0371 \%$, and that for the group of firms with low Average ESG Rating is $1.0580 \%$. As for negative news, the average industry adjusted return for group of firms with high average ESG Rating is $-0.3430 \%$, and that for the group of firms with low Average ESG Rating is $-0.4586 \%$. We note that while the broad message is similar to that considering all ESG news, the results in this panel using material ESG news are significantly stronger than those considering all ESG news. This finding is consistent with the past literature that highlights the importance of financial materiality in ESG issues and suggest that not all ESG issues are financially material for companies in a given industry (Khan et al. 2016; Grewal et al. 2020).

In Panel $\mathrm{C}$, we examine how consensus rating and disagreement affect stock reactions around ESG news. Specifically, we estimate the following regression model:

$$
\begin{aligned}
& \text { Ind Adj Ret }-1,+1_{i, t}=\beta_{0}+\beta_{1} \text { Positive News }_{i, t}+\text { Control Variables }+ \text { Date FE }+ \\
& \text { Industry FE }+\varepsilon_{i, t}(2 a) \\
& \text { Ind Adj Ret }-1,+1_{i, t}=\beta_{0}+\beta_{1} \text { Positive News } s_{i, t}+\beta_{2} \text { High Average ESG Rating } g_{i, t-1}+ \\
& \beta_{3} \text { Positive News } s_{i, t} * \text { High Average ESG Rating }{ }_{i, t-1}+\text { Control Variables }+ \text { Date FE }+ \\
& \text { Industry FE }+\varepsilon_{i, t}(2 b)
\end{aligned}
$$

where Industry Adjusted Return $-1,+1$ is the industry-adjusted return during the three-day window around ESG news. Positive (Negative) News indicates TruValue Lab's ESG news score in the highest (lowest) quintile. We define an indicator variable as the moderator to facilitate easy 
interpretation of the moderating effect. High Average ESG Rating indicates firms that have above average ESG consensus rating. All controls and fixed effects are defined as in equation 1.

Column 1 presents the result from equation 2a. The coefficient estimate on positive news is 0.0054 (t-stat: 4.391 ). This suggests that stock price reaction to positive ESG news is more positive than that on negative news as shown in Panel A and is consistent with the predictions in H3. In column 2, we present the results from equation $2 b$. The coefficient estimates on Positive News, High Average ESG Rating $\mathrm{t}_{-1}$, and Positive News * High Average ESG Rating ${ }_{\mathrm{t}-1}$ are 0.0075 (t-stat: 3.805$), 0.0017$ (t-stat: 1.497), and -0.0041 (t-stat: -2.005), respectively. This suggests that positive news is associated with 75 basis points higher stock returns than negative news; however, for firms with high ratings the return spread between positive and negative news is only 34 basis points. Overall, this demonstrates that consensus ESG ratings negatively moderates the relationship between ESG news and stock price reaction, confirming the prediction in $\mathrm{H} 4$. In columns 3 and 4, we examine equation $2 \mathrm{~b}$ separately on samples with high and low disagreement in ratings. While we find a positive and statistically coefficient on Positive News, we do not find significant coefficients on High Average ESG Ratingt-1 and Positive News * High Average ESG Rating $_{\mathrm{t}-1}$ although the sign on the latter is negative as expected.

In column 5-7, we present the results on Material News only and replicate the results in columns 2-4 that used all ESG News. In column 5, where we replicate column 2, the coefficient estimates on Positive News, High Average ESG Rating $\mathrm{t}_{-1}$, and Positive News * High Average ESG Rating $_{\mathrm{t}-1}$ are 0.0281 (t-stat: 5.443), 0.0051 (t-stat: 2.063), and -0.0202 (t-stat: -4.125), respectively. This suggests that the stock reaction spread between positive and negative news increases to $2.81 \%$ for firms with low consensus rating and the spread is 79 basis points for firms with high consensus 
rating. In addition, taken together with the results in column 2 , the results are much stronger when we consider material ESG news instead of all news.

In columns 6 and 7, we replicate columns 3 and 4. For column 6 where we use firms with high disagreement in ESG ratings, we do not find any statistically significant coefficients on Positive News, High Average ESG Rating $\mathrm{t}_{-1}$, and Positive News * High Average ESG Rating t $_{\text {. }}$ However, when we consider firms with low disagreement in ESG ratings in column 7, the

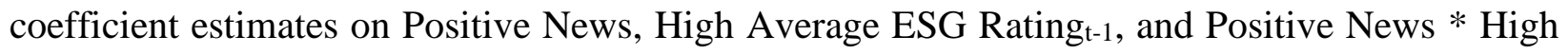
Average ESG Rating t-1 $_{\text {are }} 0.0370$ (t-stat: 3.619), 0.0133 (t-stat: 2.142), and -0.0297 (t-stat: 3.456), respectively. This suggests that the stock reaction spread between positive and negative news increases to $3.70 \%$ for firms with low consensus rating and 73 basis points for firms with high consensus rating.

We also In Panel B, we present results using equation 2 where we examine the role of ESG Consensus rating in predicting stock returns. In column 1, we find a positive market reaction to immaterial ESG news. However, the magnitude again is substantially smaller to material ESG news. Also, Average ESG Rating does not moderate the relationship between market reaction and news when immaterial news is considered. In columns 2 and 3, we examine equation 2 separately on high disagreement only and low disagreement only samples. In these specifications, we do not find that market reacts more to positive ESG news nor ESG consensus to moderate this relationship. Taken together with our main results, we conclude that our main results are driven by news that are financial material rather than immaterial news. 


\section{Pricing of ESG Ratings in the Presence of Disagreement}

Our results so far suggest that in the presence of disagreement, there is little market reaction to news and that ratings play little role in moderating that relationship. To better understand why this might be the case, we turn to analyze for the sample of high rater disagreement, which ratings predict news and whether portfolios that go long (short) on companies with the most positive (negative) difference between the most and least predictive ratings earn abnormal stock returns in the future. Documenting abnormal stock returns could be interpreted as a sign that in the presence of high disagreement, the most accurate ratings in predicting future news are slowly incorporated into prices. We first use the following empirical model to examine how the three ratings perform in predicting ESG news.

$$
\begin{aligned}
& \text { ESG News }_{i, t}=\beta_{0}+\beta_{1} \text { MSCI ESG Rating } \text { R }_{i, t-1}+\beta_{2} \text { Sustainalytics ESG Rating }_{i, t-1}+ \\
& \beta_{3} \text { Thomson ESG Rating }_{i, t-1}+\text { Control Variables }+ \text { Date FE }+ \text { Industry FE }+\varepsilon_{i, t} \text { (3) }
\end{aligned}
$$

where ESG News is the ESG news score from TruValue Labs. MSCI Rating, Sustainalytics Rating, and Thomson Rating are ESG Ratings from MSCI, Sustainalytics, and Thomson Reuters, respectively. Control variables and fixed effects are as in equations 1 and 2.

Table 5 Panel A presents the results. In columns 1-3, we first consider MSCI, Sustainalytics, and Thomson Ratings separately. The coefficient estimate on MSCI Rating in column 1 is 0.2130 (t-stat: 8.192), the coefficient estimate on Sustainalytics Rating in column 1 is 0.2736 (t-stat: 6.963), and the coefficient estimate on Thomson Rating in column 1 is 0.0819 (tstat: 1.780). This suggests that three ESG Ratings predict ESG News when considered separately, but we note that Thomson ESG Rating has the weakest predictive ability.

In column 4, we consider all three ratings in one regression and examine their predictive ability with respect to one another. The coefficient estimates on MSCI ESG Rating, Sustainalytics ESG Rating, and Thomson ESG Rating are 0.1520 (t-stat: 4.161), 0.1339 (t-stat: 3.069), and 
0.0177 (t-stat: 0.485). Thomson ESG Rating does not predict ESG News when considered with other ESG Ratings. In columns 5-8, we consider Material ESG News as the dependent variable. The overall message is similar, but we note that in column 8 where we consider all three ratings in one regression, both Sustainalytics and Thomson ESG Rating lose their predictive ability in predicting ESG News when used with MSCI ESG Rating.

Establishing that MSCI ESG Rating best predicts ESG News, we then use it as a signal to predict future stock returns. To do so, we take the firms with high disagreement among the three ratings and form long and short portfolios. Specifically, we buy the firms with MSCI ESG Ratings greater than the average of the two ratings and require MSCI ESG Rating to be above 50 (thereby likely to get positive news), and short the firms with MSCI ESG Rating smaller than the average of the two ratings and require MSCI ESG Rating to be below 50 (and thereby likely to get negative news). ${ }^{7}$ The intuition is that we use MSCI ESG Rating as the main signal because it best predicts future ESG news, especially on material ESG issues. If so, firms with high MSCI ESG Rating would exhibit higher future stock returns than firms with low MSCI ESG Rating. We estimate the following specification:

$$
R_{i, t}=\alpha+\beta_{M K T} M K T_{i, t}+\beta_{S M B} S M B_{i, t}+\beta_{H M L} H M L_{i, t}+\beta_{R M W} R M W_{i, t}+\beta_{C M A} C M A_{i, t}+\varepsilon_{i, t} \text { (4) }
$$

where $\mathrm{R}_{\mathrm{i}, \mathrm{t}}$ is the return on portfolio $\mathrm{i}$ in month $\mathrm{t}$ in excess of the risk free rate. $\mathrm{MKT}_{\mathrm{i}, \mathrm{t}}$ is the market excess return; $\mathrm{SMB}_{\mathrm{i}, \mathrm{t}}, \mathrm{HML}_{\mathrm{i}, \mathrm{t}}, \mathrm{RMW} \mathrm{W}_{\mathrm{i}, \mathrm{t}}$, and $\mathrm{CMA}_{\mathrm{i}, \mathrm{t}}$ are size, book-to-market, profitability and investment factors from Fama and French (2016). $\alpha$ is an intercept that captured the abnormal riskadjusted return.

\footnotetext{
${ }^{7}$ We restrict the long and short portfolio to have MSCI ESG Rating higher and lower than 50 respectively, because MSCI ESG Rating is constructed around an average score of 50. So, we long (short) portfolio of firms with MSCI ESG Rating above (below) the mean.
} 
The results are presented in Table 5 Panels B and C. Panel B presents the summary statistics of the long and short portfolio. In the short portfolio, average MSCI ESG Rating (36.28) is significantly lower than 66.00, which is the average between Sustainalytics and Thomson ESG Rating. In the long portfolio, average MSCI ESG Rating is 59.08, which is higher than the average between Sustainalytics and Thomson ESG Rating of 56.56. Panel C presents the result from the long/short portfolio. When using equal-weighted and value-weighted approaches, the long/short portfolio generates an annualized alpha of $4.27 \%$ and $4.00 \%$, respectively.

For robustness, we also replicate the results presented in Table 5 Panels B and C using normalized ESG ratings. We present this evidence in Appendix Table 4 Panels A and B. We find that the long/short portfolio generates an annualized alpha of $3.35 \%$ and $3.22 \%$ when using equalweighted and value-weighted approaches, respectively. Taken together with the findings in Table 5, our results suggest that future stock returns can be predicted using the most predictive ESG rating in the presence of high disagreement.

\section{CONCLUSION}

In this paper, we focus on a relatively newer set of performance evaluations: environmental, social and governance (ESG) ratings. These ratings are sourced by investment managers with trillions of dollars in assets under management influencing portfolio construction and trading. However, unlike analyst forecasts or credit ratings, it is much less clear how one can or should judge the quality of ESG ratings due to their multidimensionality and the difficulty of observing clear realizations of the outcomes.

We investigate the predictive ability of corporate ESG ratings on future ESG news. Our findings can be summarized as follows. First, we find that consensus ESG rating predicts future 
ESG news but this relationship is moderated by the extent of the disagreement between raters. Second, we find a positive market reaction to positive ESG news and negative reaction to negative news. Interestingly, we find that the market reaction to positive news is smaller for firms with high ESG rating and interpret this finding as positive news is already reflected in stock price. We also find that for firms with low disagreement, where ratings are more likely to create stronger expectations about future news, stock price reaction results are further magnified. Third, we find that ESG ratings from different providers have differential predictive ability and that rating from the provider with the most predictive power predicts future stock returns in the presence of high ratings disagreement.

Our findings suggest that ratings proxy for market expectations of future performance and predict future news and stock returns despite rating disagreement hinders their usefulness. We believe that we add to an emerging stream of literature has focused on the fact that different raters give the same company very different ratings (Berg et al. 2019; Christensen et al. 2019) raising questions about their usefulness (Chatterji et al. 2016). 


\section{REFERENCES}

Amel-Zadeh, A. and Serafeim, G., 2018. Why and how investors use ESG information: Evidence from a global survey. Financial Analysts Journal, 74(3), pp.87-103.

Baker, M., Bergstresser, D., Serafeim, G. and Wurgler, J., 2018. Financing the response to climate change: The pricing and ownership of US green bonds (No. w25194). National Bureau of Economic Research.

Barber, B., Lehavy, R., McNichols, M. and Trueman, B., 2001. Can investors profit from the prophets? Security analyst recommendations and stock returns. The Journal of Finance, 56(2), pp.531-563.

Becker, B. and Milbourn, T., 2011. How did increased competition affect credit ratings?. Journal of Financial Economics, 101(3), pp.493-514.

Berg, F., Koelbel, J.F. and Rigobon, R., 2019. Aggregate Confusion: The Divergence of ESG Ratings. Working paper.

Bradshaw, M.T., Drake, M.S., Myers, J.N. and Myers, L.A., 2012. A re-examination of analysts' superiority over time-series forecasts of annual earnings. Review of Accounting Studies, 17(4), pp.944-968.

Capelle-Blancard, G. and Petit, A., 2019. Every little helps? ESG news and stock market reaction. Journal of Business Ethics, 157(2), pp.543-565.

Chatterji, A.K., Durand, R., Levine, D.I. and Touboul, S., 2016. Do ratings of firms converge? Implications for managers, investors and strategy researchers. Strategic Management Journal, 37(8), pp.1597-1614.

Cheng, I.H., Hong, H. and Shue, K., 2013. Do managers do good with other people's money? (No. w19432). National Bureau of Economic Research.

Christensen, D., Serafeim, G. and Sikochi, A., 2019. Why is Corporate Virtue in the Eye of The Beholder? The Case of ESG Ratings. Working paper.

Clement, M.B. and Tse, S.Y., 2003. Do investors respond to analysts' forecast revisions as if forecast accuracy is all that matters?. The Accounting Review, 78(1), pp.227-249. 
Dimson, E., Karakaş, O. and Li, X., 2015. Active ownership. The Review of Financial Studies, 28(12), pp.3225-3268.

Eccles, R.G., Ioannou, I. and Serafeim, G., 2014. The impact of corporate sustainability on organizational processes and performance. Management Science, 60(11), pp.2835-2857.

Edmans, A., 2011. Does the stock market fully value intangibles? Employee satisfaction and equity prices. Journal of Financial economics, 101(3), pp.621-640.

Fama, E.F. and French, K.R., 2016. Dissecting anomalies with a five-factor model. The Review of Financial Studies, 29(1), pp.69-103.

Flammer, C., 2013. Corporate social responsibility and shareholder reaction: The environmental awareness of investors. Academy of Management Journal, 56(3), pp.758-781.

Fombrun, C. and Shanley, M., 1990. What's in a name? Reputation building and corporate strategy. Academy of management Journal, 33(2), pp.233-258.

Freeman, R.E., Harrison, J.S. and Wicks, A.C., 2007. Managing for stakeholders: Survival, reputation, and success. Yale University Press.

Fried, D. and Givoly, D. 1982. Financial analysts' forecasts of earnings: A better surrogate for market expectations. Journal of Accounting and Economics, 4(2), pp.85-107.

Friedman, M. 1970. The social responsibility of business is to increase its profits. New York Times Magazine 32 (13): 122-126.

Gleason, C.A. and Lee, C.M., 2003. Analyst forecast revisions and market price discovery. The Accounting Review, 78(1), pp.193-225.

Goh, J.C. and Ederington, L.H., 1993. Is a bond rating downgrade bad news, good news, or no news for stockholders?. The Journal of Finance, 48(5), pp.2001-2008.

Grewal, J., Hauptmann, C. and Serafeim, G., 2020. Material sustainability information and stock price informativeness. Journal of Business Ethics, pp.1-32.

Grewal, J., Riedl, E.J. and Serafeim, G., 2019. Market reaction to mandatory nonfinancial disclosure. Management Science, 65(7), pp.3061-3084. 
Healy, P.M. and Palepu, K.G., 2001. Information asymmetry, corporate disclosure, and the capital markets: A review of the empirical disclosure literature. Journal of Accounting and Economics, 31(1-3), pp.405-440.

Hong, H. and Kubik, J.D., 2003. Analyzing the analysts: Career concerns and biased earnings forecasts. The Journal of Finance, 58(1), pp.313-351.

Jensen, M. C. 2002. Value maximization, stakeholder theory, and the corporate objective function. Business Ethics Quarterly: 235-256.

Jones, G.H., Jones, B.H. and Little, P., 2000. Reputation as reservoir: Buffering against loss in times of economic crisis. Corporate Reputation Review, 3(1), pp.21-29.

Khan, M., Serafeim, G. and Yoon, A., 2016. Corporate sustainability: First evidence on materiality. The accounting review, 91(6), pp.1697-1724.

Krüger, P., 2015. Corporate goodness and shareholder wealth. Journal of financial economics, 115(2), pp.304-329.

Lee, L.F., Hutton, A.P. and Shu, S., 2015. The role of social media in the capital market: Evidence from consumer product recalls. Journal of Accounting Research, 53(2), pp.367-404.

Lins, K.V., Servaes, H. and Tamayo, A., 2017. Social capital, trust, and firm performance: The value of corporate social responsibility during the financial crisis. The Journal of Finance, 72(4), pp.1785-1824.

Mikhail, M.B., Walther, B.R. and Willis, R.H., 1999. Does forecast accuracy matter to security analysts?. The Accounting Review, 74(2), pp.185-200.

Miller, G.S., 2006. The press as a watchdog for accounting fraud. Journal of Accounting Research, 44(5), pp.1001-1033.

Naughton, J.P., Wang, C. and Yeung, I., 2019. Investor Sentiment for Corporate Social Performance. The Accounting Review, 94(4), pp.401-420.

Pinello, A.S., 2008. Investors' differential reaction to positive versus negative earnings surprises. Contemporary Accounting Research, 25(3), pp.891-920. 
Serafeim, G. 2014. Turning a profit while doing good: aligning sustainability with corporate performance. Brookings Institution.

Turban, D.B. and Greening, D.W., 1997. Corporate social performance and organizational attractiveness to prospective employees. Academy of management journal, 40(3), pp.658-672.

Werther Jr, W.B. and Chandler, D., 2005. Strategic corporate social responsibility as global brand insurance. Business Horizons, 48(4), pp.317-324. 
Table 1 Frequency Table

Panel A By Year

\begin{tabular}{lr}
\hline Year & $\mathrm{N}$ \\
\hline \hline 2010 & 1,227 \\
2011 & 1,869 \\
2012 & 1,845 \\
2013 & 2,303 \\
2014 & 3,069 \\
2015 & 5,799 \\
2016 & 5,468 \\
2017 & 6,516 \\
2018 & 3,758 \\
\hline Total & 31,854 \\
\hline
\end{tabular}

Panel B By Sector

\begin{tabular}{lr}
\hline Industry & $\mathrm{N}$ \\
\hline \hline Energy & 1,498 \\
Materials & 1,505 \\
Industrials & 2,644 \\
Consumer Discretionary & 5,632 \\
Consumer Staples & 4,078 \\
Health Care & 3,601 \\
Financials & 1,729 \\
Information Technology & 6,253 \\
Communication Services & 3,319 \\
Utilities & 1,504 \\
Real Estate & 91 \\
\hline Total & 31,854 \\
\hline
\end{tabular}




\section{Table 2 Descriptive Statistics}

This table presents the descriptive statistics. Industry Adj Return $-1,+1$ is the industry-adjusted return during the three day window around ESG news. ESG News is ESG news score from TruValue Labs. MSCI, Sustainalytics, and Thomson Reuters ESG Ratings are latest Ratings from MSCI, Sustainalytics, and Thomson, respectively. Average ESG Rating is average of the most recent ESG Ratings from MSCI, Sustainalytics, and Thomson. Disagreement is the standard deviation of the three ESG Ratings. $\log$ (Market Cap) is the log of beginning-of-day market capitalization for a firm on the day the news article is published. MTB is beginning-of-day market value over book value of equity. ROE is defined as net income over average shareholder equity. Leverage is long-term debt plus current debt over the average of total assets of the current and previous year. Capex/PPE is capital expenditure divided by property plant and equipment. SG\&A/Sales is selling, general, and administrative expense over sales. Adv Exp/Sales is advertising expense over sales. $R \& D / S a l e s$ is $R \& D$ expense over sales.

Panel A Summary Statistics

\begin{tabular}{lcccccc}
\hline & $\mathrm{N}$ & Mean & St. Dev & $\mathrm{p} 25$ & Median & $\mathrm{p} 75$ \\
\hline \hline Industry Adjusted Return -1, +1 & 31,854 & 0.00 & 0.02 & -0.01 & 0.00 & 0.01 \\
ESG News & 31,854 & 56.26 & 11.54 & 48.92 & 56.53 & 63.66 \\
MSCI ESG Rating & 31,854 & 48.47 & 12.68 & 39.00 & 47.00 & 56.70 \\
Sustainalytics ESG Rating & 30,697 & 62.22 & 8.88 & 56.00 & 63.00 & 68.00 \\
Thomson Reuters ESG Rating & 23,220 & 70.70 & 16.36 & 61.91 & 74.56 & 82.84 \\
Average ESG Rating & 31,854 & 58.76 & 10.33 & 51.28 & 58.75 & 65.50 \\
Disagreement & 31,854 & 10.28 & 5.02 & 6.50 & 10.41 & 13.54 \\
log(Market Cap) & 31,854 & 17.90 & 1.47 & 16.98 & 18.17 & 19.07 \\
MTB & 31,854 & 4.89 & 7.71 & 1.59 & 3.04 & 5.83 \\
ROE & 31,854 & 0.20 & 0.38 & 0.09 & 0.17 & 0.28 \\
Leverage & 31,854 & 0.27 & 0.16 & 0.16 & 0.26 & 0.37 \\
Capex/PPE & 31,854 & 0.12 & 0.09 & 0.06 & 0.09 & 0.15 \\
SG\&A/Sales & 31,854 & 0.22 & 0.17 & 0.07 & 0.21 & 0.35 \\
Adv Exp/Sales & 31,854 & 0.02 & 0.02 & 0.00 & 0.01 & 0.03 \\
R\&D/Sales & 31,854 & 0.06 & 0.09 & 0.00 & 0.02 & 0.12 \\
\hline
\end{tabular}




\section{Panel B Correlation Table}

\begin{tabular}{|c|c|c|c|c|c|c|c|c|c|c|c|c|c|c|c|c|}
\hline & & 1 & 2 & 3 & 4 & 5 & 6 & 7 & 8 & 9 & 10 & 11 & 12 & 13 & 14 & 15 \\
\hline 1 & Industry Adjusted Return $-1,+1$ & 1.00 & & & & & & & & & & & & & & \\
\hline 2 & ESG News & 0.04 & 1.00 & & & & & & & & & & & & & \\
\hline 3 & MSCI ESG Rating & 0.00 & 0.30 & 1.00 & & & & & & & & & & & & \\
\hline 4 & Sustainalytics ESG Rating & 0.00 & 0.25 & 0.47 & 1.00 & & & & & & & & & & & \\
\hline 5 & Thomson Reuters ESG Rating & -0.01 & 0.06 & 0.30 & 0.60 & 1.00 & & & & & & & & & & \\
\hline 6 & Average ESG Rating & 0.00 & 0.25 & 0.74 & 0.78 & 0.85 & 1.00 & & & & & & & & & \\
\hline 7 & Disagreement & 0.00 & -0.15 & -0.41 & 0.11 & 0.45 & 0.10 & 1.00 & & & & & & & & \\
\hline 8 & $\log$ (Market Cap) & -0.02 & -0.16 & 0.14 & 0.27 & 0.60 & 0.42 & 0.29 & 1.00 & & & & & & & \\
\hline 9 & MTB & 0.00 & 0.00 & 0.01 & 0.01 & 0.00 & 0.01 & 0.00 & 0.00 & 1.00 & & & & & & \\
\hline 10 & ROE & -0.03 & 0.04 & 0.08 & 0.13 & 0.21 & 0.17 & 0.05 & 0.13 & -0.05 & 1.00 & & & & & \\
\hline 11 & Leverage & 0.00 & 0.04 & -0.04 & 0.07 & 0.00 & -0.02 & 0.00 & -0.12 & 0.00 & -0.01 & 1.00 & & & & \\
\hline 12 & Capex/PPE & 0.00 & -0.05 & 0.08 & -0.20 & -0.35 & -0.16 & -0.24 & 0.06 & 0.00 & -0.04 & -0.27 & 1.00 & & & \\
\hline 13 & SG\&A/Sales & 0.01 & 0.00 & 0.00 & 0.01 & -0.02 & -0.01 & -0.01 & -0.01 & 0.00 & -0.01 & -0.01 & 0.03 & 1.00 & & \\
\hline 14 & Adv Exp/Sales & 0.00 & 0.00 & 0.03 & 0.04 & -0.05 & 0.00 & -0.06 & 0.07 & 0.02 & 0.00 & 0.06 & 0.21 & 0.00 & 1.00 & \\
\hline 15 & R\&D/Sales & 0.09 & 0.03 & -0.01 & -0.03 & -0.09 & -0.07 & -0.06 & -0.11 & -0.01 & -0.09 & 0.00 & 0.06 & 0.22 & 0.00 & 1.00 \\
\hline
\end{tabular}




\section{Table 3 Prediction of News Based on the Most Recent ESG Rating}

This table presents results from equation (1). ESG News is ESG news score from TruValue Labs. Average ESG Rating is average of the most recent ESG Ratings from MSCI, Sustainalytics, and Thomson. Disagreement is the standard deviation of the three ESG Ratings. Control variables include the following: $\log$ (Market Cap) is the log of beginningof-day market capitalization for a firm on the day the news article is published. MTB is beginning-of-day market value over book value of equity. ROE is defined as net income over average shareholder equity. Leverage is long-term debt plus current debt over the average of total assets of the current and previous year. Capex/PPE is capital expenditure divided by property plant and equipment. SG\&A/Sales is selling, general, and administrative expense over sales. Adv Exp/Sales is advertising expense over sales. $R \& D / S a l e s$ is $R \& D$ expense over sales. All models include industry and date fixed effects. Standard errors are robust to heteroscedasticity and double clustered at the firm and date level. ***, $* *, *$ are statistically significant at the 1,5 , and $10 \%$ levels, respectively.

\begin{tabular}{|c|c|c|c|c|}
\hline & \multicolumn{4}{|c|}{ News Score } \\
\hline & $(1)$ & $(2)$ & $(3)$ & (4) \\
\hline & \multicolumn{2}{|c|}{ All News } & \multicolumn{2}{|c|}{ Material News } \\
\hline Average ESG Rating ${ }_{\mathrm{t}-1}$ & $\begin{array}{c}0.2784 * * * \\
{[7.446]}\end{array}$ & $\begin{array}{c}0.3975 * * * \\
{[7.293]}\end{array}$ & $\begin{array}{c}0.2458 * * * \\
{[5.186]}\end{array}$ & $\begin{array}{c}0.4132 * * * \\
{[6.237]}\end{array}$ \\
\hline Disagreement & & $\begin{array}{c}0.6080^{* *} \\
{[2.248]}\end{array}$ & & $\begin{array}{c}0.8904 * * * \\
{[2.882]}\end{array}$ \\
\hline Average ESG Rating ${ }_{t-1} *$ Disagreement & & $\begin{array}{c}-0.0127 * * * \\
{[-2.881]}\end{array}$ & & $\begin{array}{c}-0.0167 * * * \\
{[-3.341]}\end{array}$ \\
\hline $\log ($ Market Cap) & $\begin{array}{c}-1.8206^{* * *} \\
{[-8.311]}\end{array}$ & $\begin{array}{c}-1.7202 * * * \\
{[-7.525]}\end{array}$ & $\begin{array}{c}-1.8387 * * * \\
{[-6.243]}\end{array}$ & $\begin{array}{c}-1.8009 * * * \\
{[-5.970]}\end{array}$ \\
\hline MTB & $\begin{array}{c}-0.0004 * * * \\
{[-2.868]}\end{array}$ & $\begin{array}{c}-0.0004 * * * \\
{[-3.033]}\end{array}$ & $\begin{array}{l}-0.0011 \\
{[-0.125]}\end{array}$ & $\begin{array}{c}-0.0018 \\
{[-0.207]}\end{array}$ \\
\hline ROE & $\begin{array}{l}-0.0938 \\
{[-0.268]}\end{array}$ & $\begin{array}{l}-0.0722 \\
{[-0.213]}\end{array}$ & $\begin{array}{l}0.4980 \\
{[0.970]}\end{array}$ & $\begin{array}{l}0.4759 \\
{[0.940]}\end{array}$ \\
\hline Leverage & $\begin{array}{l}-0.3049 \\
{[-0.129]}\end{array}$ & $\begin{array}{l}-0.2795 \\
{[-0.118]}\end{array}$ & $\begin{array}{l}1.5056 \\
{[0.487]}\end{array}$ & $\begin{array}{c}1.3331 \\
{[0.434]}\end{array}$ \\
\hline Capex/PPE & $\begin{array}{l}-6.4839 \\
{[-1.107]}\end{array}$ & $\begin{array}{l}-6.5286 \\
{[-1.125]}\end{array}$ & $\begin{array}{l}-8.7999 \\
{[-1.619]}\end{array}$ & $\begin{array}{l}-8.0090 \\
{[-1.471]}\end{array}$ \\
\hline SG\&A/Sales & $\begin{array}{c}-0.0097 * * * \\
{[-4.982]}\end{array}$ & $\begin{array}{c}-0.0099 * * * \\
{[-5.092]}\end{array}$ & $\begin{array}{c}-0.0099 * * * \\
{[-5.080]}\end{array}$ & $\begin{array}{c}-0.0103 * * * \\
{[-5.336]}\end{array}$ \\
\hline Adv Exp/Sales & $\begin{array}{r}-10.8767 \\
{[-1.007]}\end{array}$ & $\begin{array}{c}-10.0439 \\
{[-0.942]}\end{array}$ & $\begin{array}{c}-14.5865 \\
{[-1.022]}\end{array}$ & $\begin{array}{c}-16.1466 \\
{[-1.120]}\end{array}$ \\
\hline $\mathrm{R} \& \mathrm{D} /$ Sales & $\begin{array}{c}0.0691 \\
{[1.070]}\end{array}$ & $\begin{array}{c}0.0764 \\
{[1.192]}\end{array}$ & $\begin{array}{l}0.0776 \\
{[1.034]}\end{array}$ & $\begin{array}{l}0.0895 \\
{[1.208]}\end{array}$ \\
\hline F.E & & Indus & \& Date & \\
\hline $\mathrm{N}$ & 31,854 & 31,854 & 10,806 & 10,806 \\
\hline R-squared & 0.316 & 0.320 & 0.453 & 0.456 \\
\hline
\end{tabular}




\section{Table 4 Market Reaction to ESG News Conditional on the Average ESG Rating}

Panel A and B present the univariate analysis and panel C presents the multivariate results from equation (2). Industry Adj Return $-1,+1$ is the industry-adjusted return during the three day window around ESG news. Positive (Negative) News indicates TruValue Lab's ESG news score in the highest (lowest) quintile. Average ESG Rating is the average of the most recent ESG ratings from MSCI, Sustainalytics, and Thomson. Disagreement is the standard deviation of the three ESG ratings. Hi Average ESG Rating and Hi Disagreement indicate firms that are above average in these dimension. Control variables include the following: $\log ($ Market Cap) is the $\log$ of beginning-of-day market capitalization for a firm on the day the news article is published. MTB is beginning-of-day market value over book value of equity. ROE is defined as net income over average shareholder equity. Leverage is long-term debt plus current debt over the average of total assets of the current and previous year. Capex/PPE is capital expenditure divided by property plant and equipment. SG\&A/Sales is selling, general, and administrative expense over sales. Adv Exp/Sales is advertising expense over sales. $R \& D / S a l e s$ is $R \& D$ expense over sales. All models include industry and date fixed effects. Standard errors are robust to heteroscedasticity and double clustered at the firm and date level. ***,**,* are statistically significant at the 1,5 , and $10 \%$ levels, respectively.

Panel A. Univariate Analysis- All News

\begin{tabular}{lcccc}
\hline & \multicolumn{2}{c}{ High Average ESG Rating } & \multicolumn{2}{c}{ Low Average ESG Rating } \\
\cline { 2 - 5 } & $\mathrm{N}$ & Industry Adj Return $-1,+1$ & $\mathrm{~N}$ & Industry Adj Return -1, +1 \\
\hline \hline Positive News & 4,006 & $0.0738 \%$ & 2,365 & $0.4159 \%$ \\
Negative News & 2,379 & $-0.1890 \%$ & 3,991 & $-0.2184 \%$ \\
\hline
\end{tabular}

Panel B. Univariate Analysis- Material News

\begin{tabular}{|c|c|c|c|c|}
\hline & \multicolumn{2}{|c|}{ High Average ESG Rating } & \multicolumn{2}{|c|}{ Low Average ESG Rating } \\
\hline & $\mathrm{N}$ & Industry Adj Return $-1,+1$ & $\mathrm{~N}$ & Industry Adj Return $-1,+1$ \\
\hline Positive News & 1,340 & $0.0371 \%$ & 821 & $1.0580 \%$ \\
\hline Negative News & 798 & $-0.3430 \%$ & 1,363 & $-0.4588 \%$ \\
\hline
\end{tabular}


Panel C. Multivariate Analysis- Market Reaction to ESG News Conditional on ESG Rating

\begin{tabular}{|c|c|c|c|c|c|c|c|}
\hline & \multicolumn{7}{|c|}{ Industry Adjusted Return $-1,+1$} \\
\hline & (1) & (2) & (3) & $(4)$ & \multirow{3}{*}{$\begin{array}{c}(5) \\
\text { Material } \\
\text { News } \\
\text { Only }\end{array}$} & $(6)$ & $(7)$ \\
\hline & \multirow{2}{*}{ Base } & \multirow[t]{2}{*}{ Base/Interact } & \multirow{2}{*}{$\begin{array}{c}\text { Hi Disagree } \\
\text { Only }\end{array}$} & \multirow{2}{*}{$\begin{array}{c}\text { Lo Disagree } \\
\text { Only }\end{array}$} & & \multicolumn{2}{|c|}{ Material News Only } \\
\hline & & & & & & $\begin{array}{c}\text { Hi Disagree } \\
\text { Only }\end{array}$ & $\begin{array}{c}\text { Lo Disagree } \\
\text { Only }\end{array}$ \\
\hline Positive News & $\begin{array}{c}0.0054 * * * \\
{[4.391]}\end{array}$ & $\begin{array}{c}0.0075 * * * \\
{[3.805]}\end{array}$ & $\begin{array}{c}0.0042 * \\
{[1.836]}\end{array}$ & $\begin{array}{c}0.0086 * * * \\
{[2.587]}\end{array}$ & $\begin{array}{c}0.0281 * * * \\
{[5.443]}\end{array}$ & $\begin{array}{c}0.0104 * * \\
{[2.003]}\end{array}$ & $\begin{array}{c}0.0370 * * * \\
{[3.619]}\end{array}$ \\
\hline Hi Avg ESG Rating $\mathrm{t}_{-1}$ & & $\begin{array}{c}0.0017 \\
{[1.497]}\end{array}$ & $\begin{array}{c}0.0007 \\
{[0.424]}\end{array}$ & $\begin{array}{l}-0.0005 \\
{[-0.198]}\end{array}$ & $\begin{array}{c}0.0051 * * \\
{[2.063]}\end{array}$ & $\begin{array}{c}-0.0055^{*} \\
{[-1.841]}\end{array}$ & $\begin{array}{c}0.0133 * * \\
{[2.142]}\end{array}$ \\
\hline Positive News * Hi Avg ESG Rating & & $\begin{array}{c}-0.0041 * * \\
{[-2.005]}\end{array}$ & $\begin{array}{l}-0.0004 \\
{[-0.143]}\end{array}$ & $\begin{array}{l}-0.0042 \\
{[-1.195]}\end{array}$ & $\begin{array}{c}-0.0202 * * * \\
{[-4.125]}\end{array}$ & $\begin{array}{l}-0.0027 \\
{[-0.470]}\end{array}$ & $\begin{array}{c}-0.0297 * * * \\
{[-3.456]}\end{array}$ \\
\hline $\log$ (Market Cap) & $\begin{array}{l}-0.0007 \\
{[-1.064]}\end{array}$ & $\begin{array}{l}-0.0006 \\
{[-0.903]}\end{array}$ & $\begin{array}{l}-0.0004 \\
{[-0.367]}\end{array}$ & $\begin{array}{l}-0.0007 \\
{[-0.647]}\end{array}$ & $\begin{array}{c}0.0012 \\
{[0.977]}\end{array}$ & $\begin{array}{c}0.0007 \\
{[0.328]}\end{array}$ & $\begin{array}{c}0.0033 \\
{[1.546]}\end{array}$ \\
\hline МТВ & $\begin{array}{l}-0.0000 \\
{[-0.366]}\end{array}$ & $\begin{array}{l}-0.0000 \\
{[-0.436]}\end{array}$ & $\begin{array}{c}0.0000 \\
{[1.422]}\end{array}$ & $\begin{array}{l}-0.0001 \\
{[-1.213]}\end{array}$ & $\begin{array}{l}-0.0001 \\
{[-1.226]}\end{array}$ & $\begin{array}{c}0.0001 \\
{[0.903]}\end{array}$ & $\begin{array}{l}-0.0001 \\
{[-1.069]}\end{array}$ \\
\hline ROE & $\begin{array}{l}-0.0024 \\
{[-1.353]}\end{array}$ & $\begin{array}{l}-0.0024 \\
{[-1.369]}\end{array}$ & $\begin{array}{l}-0.0060 \\
{[-1.455]}\end{array}$ & $\begin{array}{l}-0.0005 \\
{[-0.421]}\end{array}$ & $\begin{array}{l}-0.0024 \\
{[-0.852]}\end{array}$ & $\begin{array}{l}-0.0080 \\
{[-1.228]}\end{array}$ & $\begin{array}{c}0.0003 \\
{[0.078]}\end{array}$ \\
\hline Leverage & $\begin{array}{c}0.0033 \\
{[0.537]}\end{array}$ & $\begin{array}{c}0.0034 \\
{[0.559]}\end{array}$ & $\begin{array}{c}0.0219 * \\
{[1.838]}\end{array}$ & $\begin{array}{l}-0.0051 \\
{[-0.682]}\end{array}$ & $\begin{array}{l}-0.0087 \\
{[-0.789]}\end{array}$ & $\begin{array}{l}-0.0023 \\
{[-0.135]}\end{array}$ & $\begin{array}{l}-0.0213 \\
{[-1.329]}\end{array}$ \\
\hline Capex/PPE & $\begin{array}{l}-0.0009 \\
{[-0.063]}\end{array}$ & $\begin{array}{l}-0.0003 \\
{[-0.024]}\end{array}$ & $\begin{array}{c}0.0217 * \\
{[1.668]}\end{array}$ & $\begin{array}{l}-0.0094 \\
{[-0.496]}\end{array}$ & $\begin{array}{c}0.0401 \\
{[1.365]}\end{array}$ & $\begin{array}{c}0.0296 \\
{[1.123]}\end{array}$ & $\begin{array}{c}0.0603 \\
{[1.455]}\end{array}$ \\
\hline SG\&A/Sales & $\begin{array}{l}-0.0000 \\
{[-1.022]}\end{array}$ & $\begin{array}{l}-0.0000 \\
{[-0.961]}\end{array}$ & $\begin{array}{c}0.0065 \\
{[0.466]}\end{array}$ & $\begin{array}{l}-0.0000 \\
{[-0.604]}\end{array}$ & $\begin{array}{l}-0.0000 \\
{[-1.445]}\end{array}$ & $\begin{array}{l}-0.0189 \\
{[-0.654]}\end{array}$ & $\begin{array}{l}-0.0000 \\
{[-0.644]}\end{array}$ \\
\hline Adv Exp/Sales & $\begin{array}{c}0.0432 \\
{[1.389]}\end{array}$ & $\begin{array}{c}0.0447 \\
{[1.435]}\end{array}$ & $\begin{array}{c}0.0218 \\
{[0.398]}\end{array}$ & $\begin{array}{l}0.0225 \\
{[0.684]}\end{array}$ & $\begin{array}{c}0.2184 * * * \\
{[3.017]}\end{array}$ & $\begin{array}{c}0.2588 * \\
{[1.871]}\end{array}$ & $\begin{array}{c}0.1678 * \\
{[1.671]}\end{array}$ \\
\hline R\&D/Sales & $\begin{array}{c}0.0011 * * * \\
{[2.807]}\end{array}$ & $\begin{array}{c}0.0011 * * * \\
{[2.790]}\end{array}$ & $\begin{array}{c}0.0024 \\
{[0.103]}\end{array}$ & $\begin{array}{c}0.0010 * * \\
{[2.302]}\end{array}$ & $\begin{array}{c}0.0012 * * * \\
{[2.965]}\end{array}$ & $\begin{array}{l}-0.0199 \\
{[-0.552]}\end{array}$ & $\begin{array}{c}0.0013 * * \\
{[2.474]}\end{array}$ \\
\hline $\mathrm{FE}$ & & & & dustry \& Date & & & \\
\hline Observations & 12,741 & 12,741 & 6,120 & 6,621 & 4,322 & 2,089 & 2,233 \\
\hline R-squared & 0.172 & 0.173 & 0.297 & 0.276 & 0.396 & 0.600 & 0.597 \\
\hline
\end{tabular}




\section{Table 5 Prediction of News Based on the Most Recent ESG Rating-}

Panel A presents results from equation (3). ESG News is the ESG news score from TruValue Labs. ESG Ratings are latest Ratings from MSCI, Sustainalytics, and Thomson. Control variables include the following: $\log$ (Market Cap) is the log of beginning-of-day market capitalization for a firm on the day the news article is published. MTB is beginning-of-day market value over book value of equity. ROE is defined as net income over average shareholder equity. Leverage is longterm debt plus current debt over the average of total assets of the current and previous year. Capex/PPE is capital expenditure divided by property plant and equipment. SG\&A/Sales is selling, general, and administrative expense over sales. Adv Exp/Sales is advertising expense over sales. R\&D/Sales is R\&D expense over sales. All models include industry and date fixed effects. Standard errors are robust to heteroscedasticity and double clustered at the firm and date level. $* * *$, $* *$, are statistically significant at the 1,5 , and $10 \%$ levels, respectively.

Panel A. Using Individual ESG Ratings from Each Vendors

\begin{tabular}{|c|c|c|c|c|c|c|c|c|}
\hline & \multicolumn{4}{|c|}{ ESG News } & \multicolumn{4}{|c|}{ Material ESG News } \\
\hline & (1) & (2) & (3) & (4) & (5) & $(6)$ & (7) & $(8)$ \\
\hline \multirow[t]{2}{*}{ MSCI ESG Rating ${ }_{\mathrm{t}-1}$} & $0.2130 * * *$ & & & $0.1520 * * *$ & $0.2344 * * *$ & & & $0.2045 * * *$ \\
\hline & {$[8.192]$} & & & [4.161] & {$[6.593]$} & & & [4.820] \\
\hline \multirow[t]{2}{*}{ Sustainalytics ESG Rating ${ }_{t-1}$} & & $0.2736 * * *$ & & $0.1339 * * *$ & & $0.2231 * * *$ & & 0.0806 \\
\hline & & {$[6.963]$} & & {$[3.069]$} & & {$[4.377]$} & & [1.638] \\
\hline \multirow{2}{*}{ Thomson ESG Rating $\mathrm{t}-1$} & & & $0.0819 *$ & 0.0177 & & & 0.0456 & -0.0119 \\
\hline & & & {$[1.780]$} & {$[0.485]$} & & & {$[0.966]$} & {$[-0.347]$} \\
\hline \multirow[t]{2}{*}{ log(Market Cap) } & $-1.1095 * * *$ & $-1.3146^{* * *}$ & $-1.7957 * * *$ & $-1.4885 * * *$ & $-1.2550 * * *$ & $-1.4307 * * *$ & $-1.6122 * * *$ & $-1.2884 * * *$ \\
\hline & {$[-5.665]$} & {$[-5.150]$} & {$[-4.619]$} & {$[-4.307]$} & {$[-4.745]$} & {$[-4.167]$} & {$[-3.820]$} & {$[-3.302]$} \\
\hline \multirow[t]{2}{*}{ MTB } & $-0.0004 * * *$ & $-0.0004 * *$ & $-0.0004 * *$ & $-0.0004 * * *$ & -0.0039 & -0.0103 & 0.0134 & 0.0084 \\
\hline & {$[-3.095]$} & {$[-2.405]$} & {$[-2.318]$} & {$[-3.478]$} & {$[-0.492]$} & {$[-1.048]$} & [1.346] & {$[0.931]$} \\
\hline \multirow[t]{2}{*}{ ROE } & 0.1088 & -0.1233 & -0.3865 & -0.2510 & $0.7753 *$ & 0.5720 & -0.0791 & 0.8848 \\
\hline & {$[0.324]$} & {$[-0.344]$} & {$[-1.060]$} & {$[-0.719]$} & [1.687] & {$[1.075]$} & {$[-0.124]$} & [1.371] \\
\hline \multirow[t]{2}{*}{ Leverage } & 0.2697 & -0.2168 & 0.8312 & 2.4328 & 2.1598 & 1.3358 & 2.5763 & 3.8996 \\
\hline & [0.107] & {$[-0.088]$} & {$[0.341]$} & [1.025] & [0.682] & [0.399] & {$[0.754]$} & [1.108] \\
\hline \multirow[t]{2}{*}{ Capex/PPE } & $-10.9038 * *$ & -8.1894 & -11.6734 & $-11.8065^{*}$ & $-10.2442 * *$ & $-13.8563 * *$ & $-11.6574 * *$ & $-11.3830^{* *}$ \\
\hline & {$[-2.237]$} & {$[-1.208]$} & {$[-1.604]$} & {$[-1.790]$} & [-2.233] & {$[-2.075]$} & {$[-2.155]$} & {$[-2.066]$} \\
\hline \multirow[t]{2}{*}{ SG\&A/Sales } & $-0.0100 * * *$ & 1.3503 & $-0.0083 * * *$ & $8.3395 * * *$ & $-0.0102 * * *$ & 0.4676 & $-0.0094 * * *$ & $8.6981 * *$ \\
\hline & {$[-5.352]$} & {$[0.935]$} & {$[-4.099]$} & {$[2.701]$} & {$[-5.423]$} & {$[0.513]$} & {$[-4.682]$} & {$[2.206]$} \\
\hline \multirow[t]{2}{*}{ Adv Exp/Sales } & -6.6131 & -10.0501 & $-21.0643^{*}$ & $-29.3844 * *$ & -10.6480 & -24.2973 & -23.7584 & $-52.3401 * *$ \\
\hline & {$[-0.630]$} & {$[-0.794]$} & {$[-1.733]$} & {$[-2.201]$} & {$[-0.796]$} & {$[-1.283]$} & {$[-1.368]$} & {$[-2.384]$} \\
\hline \multirow[t]{2}{*}{ R\&D/Sales } & 0.0555 & 0.1908 & 0.0222 & 0.1303 & 0.0578 & 0.3029 & 0.0295 & 0.1923 \\
\hline & {$[0.880]$} & {$[0.735]$} & [0.339] & {$[0.273]$} & {$[0.793]$} & {$[1.201]$} & {$[0.401]$} & {$[0.410]$} \\
\hline $\mathrm{FE}$ & \multicolumn{8}{|c|}{ Industry \& Date } \\
\hline Observations & 31,854 & 30,697 & 23,220 & 22,063 & 10,806 & 10,469 & 7,458 & 7,121 \\
\hline R-squared & 0.319 & 0.328 & 0.330 & 0.379 & 0.461 & 0.465 & 0.499 & 0.554 \\
\hline
\end{tabular}


Panel B. Summary Stats of Long/Short Portfolios that Use Disagreements in ESG Ratings

Panel B presents the summary statistics and panel B reports alphas, factor loadings, and t-statistics from equation (4) where we restrict the sample to firms with high disagreement in ratings and use monthly calendar-time Fama-French five factor regressions for equal- and value-weighted portfolios. ESG Ratings are latest Ratings from MSCI, Sustainalytics, and Thomson. Average(Sustainalytics, Thomson) is the average of Sustainalytics and Thomson ESG Ratings. Long Portfolio includes firms with MSCI rating greater than 50 and also greater than the average of other two ratings. Short Portfolio includes firms with MSCI rating smaller than 50 and also smaller than the average of other two ratings. The regressions are estimated from January 2011 to December 2019. Market is the market excess return; SMB, HML, RMW and CMA are size, book to market, profitability and investment factors from Fama and French (2016). ***, **, * are statistically significant at the 1,5 , and $10 \%$ levels, respectively.

\begin{tabular}{lccccccc}
\hline Short Portfolio & Mean & St. Dev & Min & 0.25 & Median & 0.75 & Max \\
\hline \hline MSCI ESG Rating & 36.28 & 9.33 & 0.00 & 30.00 & 38.00 & 44.00 & 49.80 \\
Sustainalytics ESG Rating & 58.20 & 7.38 & 38.00 & 53.00 & 58.00 & 64.00 & 82.00 \\
Thomson ESG Rating & 73.80 & 16.55 & 13.74 & 66.57 & 77.83 & 86.47 & 95.39 \\
Average (Sustainalytics, Thomson) & 66.00 & 10.57 & 30.69 & 60.00 & 67.90 & 73.91 & 87.65 \\
\hline
\end{tabular}

\begin{tabular}{lccccccc}
\hline Long Portfolio & Mean & St. Dev & Min & 0.25 & Median & 0.75 & Max \\
\hline \hline MSCI ESG Rating & 59.08 & 7.84 & 50.20 & 53.00 & 56.00 & 63.00 & 94.50 \\
Sustainalytics ESG Rating & 58.19 & 10.62 & 38.00 & 49.00 & 57.00 & 66.00 & 88.00 \\
Thomson ESG Rating & 44.90 & 27.43 & 6.11 & 26.01 & 31.48 & 78.37 & 95.61 \\
Average (Sustainalytics, Thomson) & 56.56 & 17.45 & 27.48 & 39.95 & 52.88 & 73.66 & 89.38 \\
\hline
\end{tabular}

Panel C. Predicting Future Stock Returns Using Disagreements in ESG Ratings

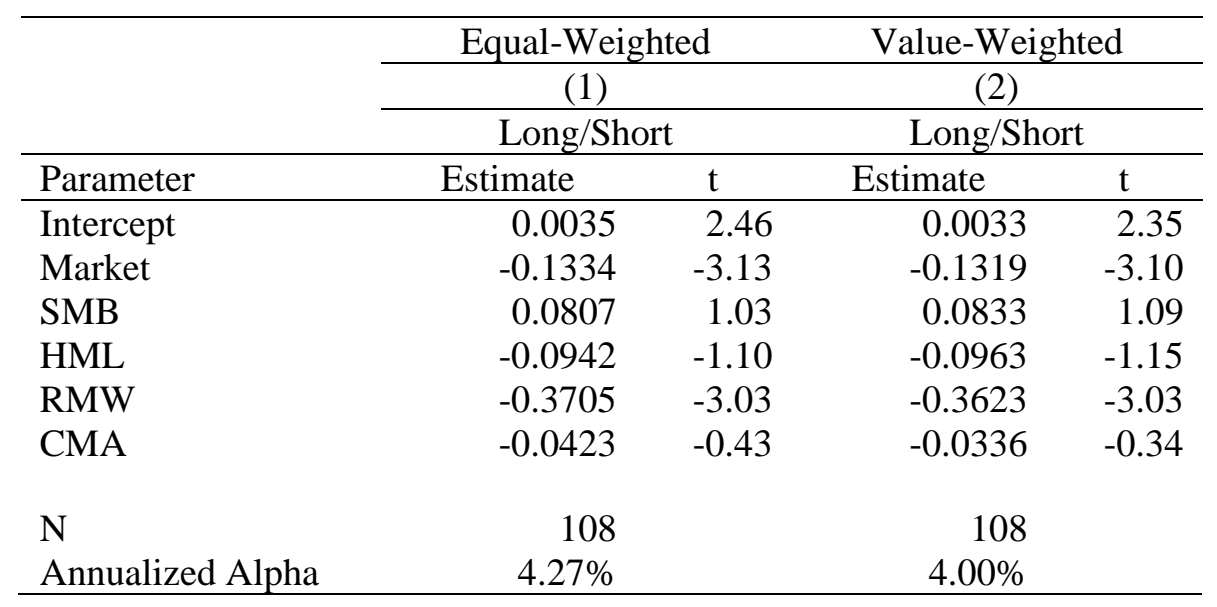




\section{Appendix}

\section{Table 1 Replication of Table 3 Using Normalized ESG Rating}

This table presents results from equation (1). ESG News is ESG news score from TruValue Labs. Unlike Table 3, the ESG Scores in this table are normalized. Average ESG Rating is average of the most recent normalized ESG Ratings from MSCI, Sustainalytics, and Thomson. Disagreement is the standard deviation of the three ESG Ratings. Control variables include the following: $\log ($ Market Cap) is the log of beginning-of-day market capitalization for a firm on the day the news article is published. MTB is beginning-of-day market value over book value of equity. ROE is defined as net income over average shareholder equity. Leverage is long-term debt plus current debt over the average of total assets of the current and previous year. Capex/PPE is capital expenditure divided by property plant and equipment. SG\&A/Sales is selling, general, and administrative expense over sales. Adv Exp/Sales is advertising expense over sales. R\&D/Sales is R\&D expense over sales. All models include industry and date fixed effects. Standard errors are robust to heteroscedasticity and double clustered at the firm and date level. ***,**,* are statistically significant at the 1,5 , and $10 \%$ levels, respectively.

\begin{tabular}{|c|c|c|c|c|}
\hline & \multicolumn{4}{|c|}{ News Score } \\
\hline & $(1)$ & $(2)$ & (3) & $(4)$ \\
\hline & \multicolumn{2}{|c|}{ All News } & \multicolumn{2}{|c|}{ Material News } \\
\hline Average ESG Rating ${ }_{t-1}$ & $\begin{array}{c}2.9563 * * * \\
{[7.352]}\end{array}$ & $\begin{array}{c}5.2441 * * * \\
{[8.274]}\end{array}$ & $\begin{array}{c}2.5859 * * * \\
{[4.935]}\end{array}$ & $\begin{array}{c}5.2434 * * * \\
{[5.953]}\end{array}$ \\
\hline Disagreement & & $\begin{array}{l}1.0687 \\
{[1.229]}\end{array}$ & & $\begin{array}{c}2.2232^{*} \\
{[1.933]}\end{array}$ \\
\hline Average ESG Rating t $-1^{*}$ Disagreement & & $\begin{array}{c}-2.4368 * * * \\
{[-4.687]}\end{array}$ & & $\begin{array}{c}-2.8407 * * * \\
{[-3.560]}\end{array}$ \\
\hline $\log ($ Market Cap) & $\begin{array}{c}-1.6664 * * * \\
{[-7.744]}\end{array}$ & $\begin{array}{c}-1.7322 * * * * \\
{[-8.146]}\end{array}$ & $\begin{array}{c}-1.6916 * * * \\
{[-5.606]}\end{array}$ & $\begin{array}{c}-1.8051 * * * \\
{[-6.042]}\end{array}$ \\
\hline MTB & $\begin{array}{c}-0.0004 * * * \\
{[-2.599]}\end{array}$ & $\begin{array}{c}-0.0004 * * \\
{[-2.567]}\end{array}$ & $\begin{array}{l}-0.0019 \\
{[-0.199]}\end{array}$ & $\begin{array}{l}-0.0044 \\
{[-0.455]}\end{array}$ \\
\hline ROE & $\begin{array}{l}-0.0763 \\
{[-0.218]}\end{array}$ & $\begin{array}{l}-0.0492 \\
{[-0.140]}\end{array}$ & $\begin{array}{c}0.5017 \\
{[0.930]}\end{array}$ & $\begin{array}{l}0.6167 \\
{[1.123]}\end{array}$ \\
\hline Leverage & $\begin{array}{l}-0.1537 \\
{[-0.065]}\end{array}$ & $\begin{array}{l}-0.0553 \\
{[-0.025]}\end{array}$ & $\begin{array}{l}1.4984 \\
{[0.456]}\end{array}$ & $\begin{array}{c}1.9196 \\
{[0.621]}\end{array}$ \\
\hline Capex/PPE & $\begin{array}{l}-6.3265 \\
{[-1.089]}\end{array}$ & $\begin{array}{l}-7.0871 \\
{[-1.327]}\end{array}$ & $\begin{array}{l}-8.7824 \\
{[-1.486]}\end{array}$ & $\begin{array}{c}-8.8120^{*} \\
{[-1.707]}\end{array}$ \\
\hline SG\&A/Sales & $\begin{array}{c}-0.0098 * * * \\
{[-4.840]}\end{array}$ & $\begin{array}{c}-0.0102 * * * \\
{[-5.227]}\end{array}$ & $\begin{array}{c}-0.0098 * * * \\
{[-4.778]}\end{array}$ & $\begin{array}{c}-0.0102 * * * \\
{[-5.076]}\end{array}$ \\
\hline Adv Exp/Sales & $\begin{array}{c}-12.3733 \\
{[-1.087]}\end{array}$ & $\begin{array}{c}-13.6483 \\
{[-1.232]}\end{array}$ & $\begin{array}{c}-15.2681 \\
{[-0.953]}\end{array}$ & $\begin{array}{c}-19.5846 \\
{[-1.328]}\end{array}$ \\
\hline $\mathrm{R} \& \mathrm{D} / \mathrm{Sales}$ & $\begin{array}{c}0.0470 \\
{[0.726]}\end{array}$ & $\begin{array}{l}0.0466 \\
{[0.729]}\end{array}$ & $\begin{array}{c}0.0550 \\
{[0.736]}\end{array}$ & $\begin{array}{c}0.0495 \\
{[0.673]}\end{array}$ \\
\hline F.E & & Indus & Date & \\
\hline $\mathrm{N}$ & 31,854 & 31,854 & 10,806 & 10,806 \\
\hline R-squared & 0.318 & 0.325 & 0.453 & 0.463 \\
\hline
\end{tabular}




\section{Table 2 Prediction of News Based on the Most Recent ESG Rating Using Quintile and Decile}

This table presents results from equation (1). ESG News is the ESG news score from TruValue Labs. Average ESG Rating is average of the most recent ESG Ratings from MSCI, Sustainalytics, and Thomson and we cut the sample into quintile and deciles using the average ESG Rating. Control variables include the following: Log(Market Cap) is the log of beginning-of-day market capitalization for a firm on the day the news article is published. MTB is beginningof-day market value over book value of equity. ROE is defined as net income over average shareholder equity. Leverage is long-term debt plus current debt over the average of total assets of the current and previous year. Capex/PPE is capital expenditure divided by property plant and equipment. SG\&A/Sales is selling, general, and administrative expense over sales. Adv Exp/Sales is advertising expense over sales. R\&D/Sales is R\&D expense over sales. All models include industry and date fixed effects. Standard errors are robust to heteroscedasticity and double clustered at the firm and date level. $* * *, * * *$ are statistically significant at the 1,5 , and $10 \%$ levels, respectively.

\begin{tabular}{|c|c|c|}
\hline \multirow[b]{2}{*}{ Avg ESG Rating $_{\mathrm{t}-1}$} & \multicolumn{2}{|c|}{ ESG News } \\
\hline & $(1)$ & (2) \\
\hline Quintile 2 & $\begin{array}{c}3.1534 * * * \\
{[3.598]}\end{array}$ & \\
\hline Quintile 3 & $\begin{array}{c}3.6344 * * * \\
{[3.778]}\end{array}$ & \\
\hline Quintile 4 & $\begin{array}{c}5.2014 * * * \\
{[5.996]}\end{array}$ & \\
\hline Quintile 5 & $\begin{array}{c}7.4100 * * * \\
{[6.757]}\end{array}$ & \\
\hline Decile 2 & & $\begin{array}{c}2.2505 * * \\
{[2.335]}\end{array}$ \\
\hline Decile 3 & & $\begin{array}{c}4.6319 * * * \\
{[3.592]}\end{array}$ \\
\hline Decile 4 & & $\begin{array}{c}4.3822 * * * \\
{[3.567]}\end{array}$ \\
\hline Decile 5 & & $\begin{array}{c}4.9497 * * * \\
{[3.521]}\end{array}$ \\
\hline Decile 6 & & $\begin{array}{c}5.0948 * * * \\
{[4.474]}\end{array}$ \\
\hline Decile 7 & & $\begin{array}{c}6.5123 * * * \\
{[5.809]}\end{array}$ \\
\hline Decile 8 & & $\begin{array}{c}6.6853 * * * \\
{[6.002]}\end{array}$ \\
\hline Decile 9 & & $\begin{array}{c}8.4838 * * * \\
{[6.681]}\end{array}$ \\
\hline Decile 10 & & $\begin{array}{c}9.4006 * * * \\
{[6.627]}\end{array}$ \\
\hline Controls & & \\
\hline F.E & Indu & Date \\
\hline $\mathrm{N}$ & 31,854 & 31,854 \\
\hline R-squared & 0.315 & 0.317 \\
\hline
\end{tabular}




\section{Table 3 Replication of Table 3 and 4 Using Immaterial News}

Panels A and B present results from equation (1a), (1b), and equation (2). ESG News score is the ESG news score from TruValue Labs. Average ESG Rating is average of the most recent ESG Ratings from MSCI, Sustainalytics, and Thomson. Disagreement is the standard deviation of the three ESG Ratings. Industry Adj Return $-1,+1$ is the industryadjusted return during the three day window around ESG news. Positive (Negative) News indicates TruValue Lab's news score in the highest (lowest) quintile. Average ESG Rating is the average of the most recent ESG Ratings from MSCI, Sustainalytics, and Thomson. Control variables include the following: $\log$ (Market Cap) is the $\log$ of beginning-of-day market capitalization for a firm on the day the news article is published. MTB is beginning-of-day market value over book value of equity. ROE is defined as net income over average shareholder equity. Leverage is long-term debt plus current debt over the average of total assets of the current and previous year. Capex/PPE is capital expenditure divided by property plant and equipment. SG\&A/Sales is selling, general, and administrative expense over sales. Adv Exp/Sales is advertising expense over sales. R\&D/Sales is R\&D expense over sales. All models include industry and date fixed effects. Standard errors are robust to heteroscedasticity and double clustered at the firm and date level. ***, **, * are statistically significant at the 1,5 , and $10 \%$ levels, respectively.

Panel A. Prediction of News Based on the Most Recent ESG Rating

\begin{tabular}{|c|c|c|}
\hline & \multicolumn{2}{|c|}{ Immaterial ESG News } \\
\hline & $(1)$ & $(2)$ \\
\hline Average ESG Rating ${ }_{t-1}$ & $\begin{array}{c}0.2930 * * * \\
{[7.842]}\end{array}$ & $\begin{array}{c}0.3770 * * * \\
{[6.668]}\end{array}$ \\
\hline Disagreement & & $\begin{array}{l}0.3766 \\
{[1.348]}\end{array}$ \\
\hline Average ESG Rating ${ }_{\mathrm{t}-1} *$ Disagreement & & $\begin{array}{c}-0.0091 * * \\
{[-1.983]}\end{array}$ \\
\hline Controls & & \\
\hline F.E & Indust & Date \\
\hline $\mathrm{N}$ & 21,048 & 21,048 \\
\hline R-squared & 0.323 & 0.326 \\
\hline
\end{tabular}


Panel B. Market Reaction to ESG News Conditional on ESG Rating

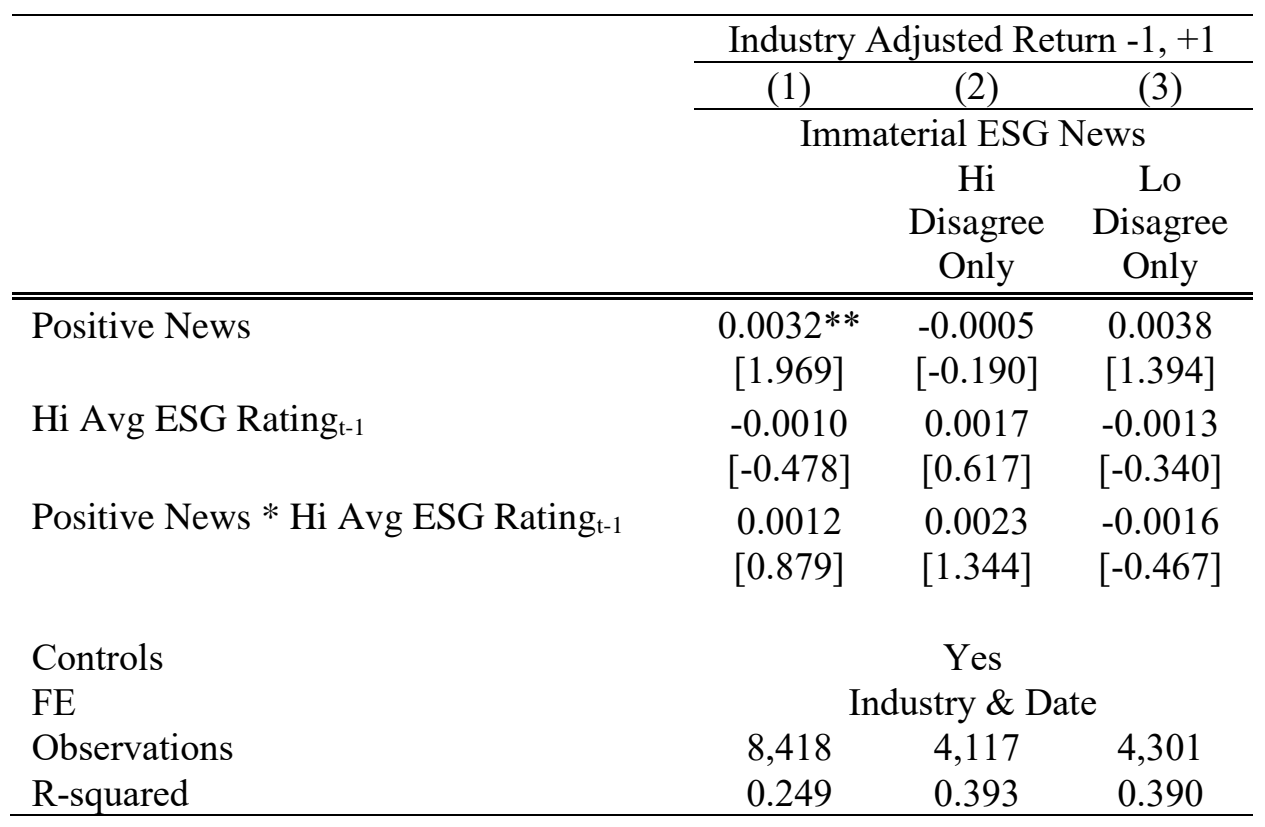




\section{Table 4 Replication of Table 5B and 5C Using Normalized ESG Scores}

Panel A presents the summary statistics and panel B reports alphas, factor loadings, and t-statistics from equation (4) where we restrict the sample to firms with high disagreement in normalized ratings and use monthly calendar-time Fama-French five factor regressions for equal- and value-weighted portfolios. ESG Ratings are latest normalized ratings from MSCI, Sustainalytics, and Thomson. Average(Sustainalytics, Thomson) is the average of normalized Sustainalytics and Thomson ESG Ratings. Long Portfolio includes firms with normalized MSCI rating greater than 0 and also greater than the average of other two ratings. Short Portfolio includes firms with normalized MSCI rating smaller than 0 and also smaller than the average of other two ratings. The regressions are estimated from January 2011 to December 2019. Market is the market excess return; SMB, HML, RMW and CMA are size, book to market, profitability and investment factors from Fama and French (2016). ***,**,* are statistically significant at the 1, 5, and $10 \%$ levels, respectively.

Panel A. Summary Stats of Long/Short Portfolios that Use Disagreements in Normalized ESG Ratings

\begin{tabular}{lccccccc}
\hline Short Portfolio & Mean & St. Dev & Min & 0.25 & Median & 0.75 & Max \\
\hline \hline MSCI ESG Score & -1.13 & 0.69 & -3.98 & -1.61 & -1.03 & -0.59 & -0.01 \\
Sustainalytics ESG Score & 0.03 & 0.95 & -2.50 & -0.74 & -0.04 & 0.78 & 3.12 \\
Thomson ESG Score & 0.55 & 0.86 & -1.55 & -0.18 & 0.74 & 1.29 & 1.80 \\
Average (Sustainalytics, Thomson) & 0.29 & 0.81 & -1.62 & -0.37 & 0.34 & 0.93 & 2.34 \\
\hline
\end{tabular}

\begin{tabular}{lccccccc}
\hline Long Portfolio & Mean & St. Dev & Min & 0.25 & Median & 0.75 & Max \\
\hline \hline MSCI ESG Score & 0.78 & 0.68 & 0.00 & 0.26 & 0.60 & 1.11 & 4.03 \\
Sustainalytics ESG Score & -0.35 & 1.04 & -2.03 & -0.98 & -0.74 & -0.04 & 3.83 \\
Thomson ESG Score & -0.48 & 0.84 & -1.86 & -1.05 & -0.75 & -0.14 & 1.81 \\
Average (Sustainalytics, Thomson) & -0.35 & 0.67 & -1.55 & -0.82 & -0.48 & 0.03 & 2.64 \\
\hline
\end{tabular}

Panel B. Predicting Future Stock Returns Using Disagreements in Normalized ESG Ratings

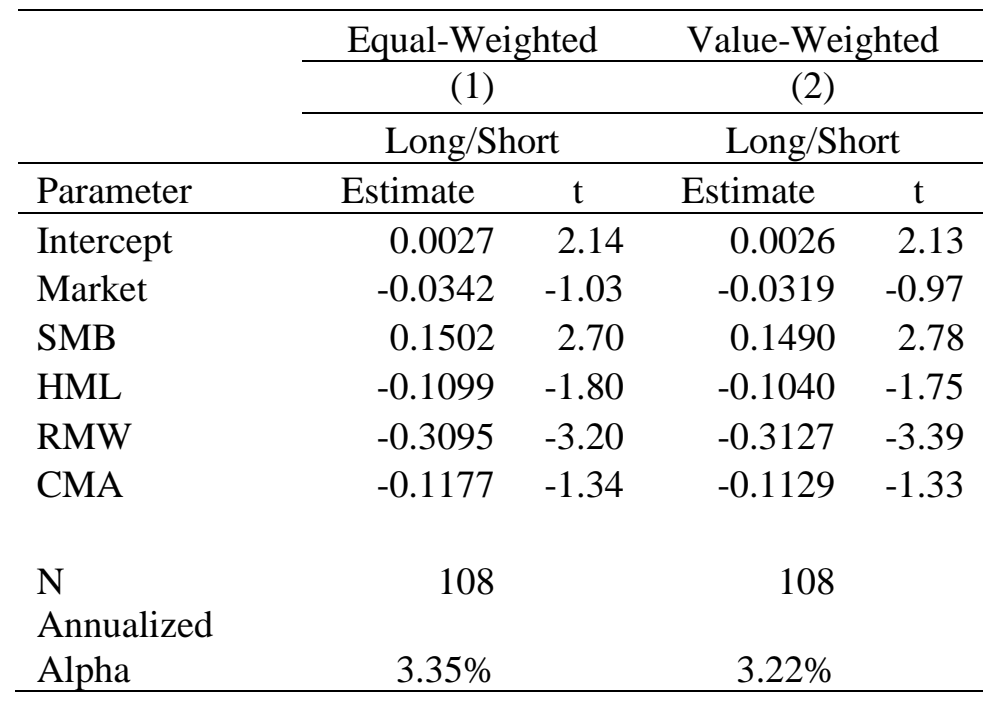

